Lição inaugural (1) e Theses Geraes de Philosophia do Direito, pelo lente cathedraticoDr. João Pedro da Veiga Eilho, em 29 de Maio de 1908.

\title{
Snrs. Peademicos:
}

Nomeado, por decr. de $2 \mathrm{I}$ do corrente mez, para reger esta cadeira de Philosophia do Direito e tendo tomado posse de tão honroso cargo perante a douta Congregação da Faculdade, venho, neste momento, iniciar o nosso curso, sob a dúpla emoção de um sincero prazer, e de úma natural hesitação!

Prazer e hesitação, pórque bem comprehendo a immensa responsabilidade que me cabe, no cumprimento de um dever profissional, junto á mocidade e no preencher um cargo tão altamente nobilitado pelo meu illustre predecessor:

Assumo, hoje, a cathedra em que, durante largos annos, conquistou opulenta messe de immarcessiveis louros, o illustrado Dr. Pedro Lessa, que, pelo seu vasto saber juridico, foi convidado, pelo governo da Republica, para exercer a suprema magistratura do mais elevado tribunal de justiça do paiz.

$\mathrm{O}$ grande constrangimento e a perplexidace que devo sentir na substituição daquelle eminente professor

(1) Tachigrafado por Manoel Alves de Souza. 


\section{- I6 -}

decorrem, principalmente, da circumstancia de ter sido, até hoje, bem differente a preferencia dada por mim a outros estudos sociaes, e náo menos diversa a orienlação de minha actividade intellectual.

Após um disputado concurso, em 1893 , fui nomeado lente substituto da $4 \cdot{ }^{a}$ secção da Faculdade, secção que, segundo o regimen da reforma do ensino de 2 de Janeiro de I89 I, comprehendia as seguintes materias: - economia politica, sciencia das finanças, contabilidade do Estado, sciencia da administração e direito administrativo. No fim de quatro annos de exercicio do magisterio, em consequencia de uma nova reforma de ensino, contrariada a minha unica aspiração ou vocação, fui nomeado para reger uma cadeira bem extranha áquella-a de Historia Geral de Direito e especialmente do Direito Nacional-cadeira então vaga, pelo tallecimento do inolvidavel e preclaro mestre Dr. Aureliano Coutinho.

Mal tinha reunido os materiaes indispensaveis e organisado um curso didactico bem regular, apenas decorrido outro quatriennio, pela reforma de I90I, fui declarado em disponibilidade, por ter sido supprimida aquella utilissima cadeira de Historia Geral do Direito, com surpreza de minha parte. Assim manifesto-me porquanto, embora não seja uma divisão scientifica, jamais comprehendi a integridade dos estudos juridicos, sem o triplice conhecimento da philosopha do direito, que expõe o direito ideal, ou o direito que deve ser; da dogmatica juridica, que expõe o direito concretisado nas leis positivas; e finalmente da historia do direito, ou a exposição do direito como elle tem sido progressivamente concebido e actuado, no tempo e no espaço (I).

(1) Dr. Aureliano Coutinho-Discurso Inaugural de Hist. do Direito, 1896, pag. 10. A. Roussel-Encyclnpèdie du Droit--pag. 167. 
Como vêm os senhores, estou de posse de uma cadeira bem diversa de anteriores estudos, accrescendo ainda, que ella jamais pertenceu ao quadro das disciplinas do antigo curso academico, de cujo ensino, aliás, fazia parte, o estudo do direito natural, ex-vi da lei de I I de Agosto de I827, que determinou a fundação das duas primeiras academias, uma ao norte, outra ao sul do paiz.

Tenho bem viva recordação do meu curso de direito natural, professado, interinamente, no primeiro anno juridico de I88I, pelo egregio lente Dr. Rubino de Oliveira, de saudosissima memoria. O compendio adoptado era o do jurisconsulto portuguez Vicente Ferrer, e o expositor mais recommendado era o do professor allemão Henri Ahrens, que, nas suas primeiras paginas, confundindo a philosophia do direito com o direito natural, assim definia:- La philosophie du droit, ou le droit naturel, est la science que expose les premiers principes du droit conçus par la raison et fondés dans la nature de l'homme, considérée en elle même et dans ses rapports avec l'ordre universel des choses" (I).

Por essa noção, é bem de ver que, nesse primeiro anno, desde o laureado professor até o mais obscuro dos alumnos, quasi todos eram racionalistas convencidos, senão extremados. Um episodio, aliás interessante, dará perfeita ideia dos principios philosophicos dominantes em nosso minusculo mundo academico. Tratavamos, nós, da fundaçâo de um club e do seu respectivo orgam de publicidade. Em circumstancias taes, uma legenda constituia a primeira e indeclinavel necessidade para o. successo do generoso commettimento. Sem ella, não podia ser concebido o fron-

(1) Henri Ahrens-Cours de Droit Naturel ou de Philosophie du Droit, vol. I, pag. 1. 
tispicio do jornal. Estabelecida, a proposito, uma discussão preliminar, um dos nossos collegas, o meu mallogrado amigo Dr. Borja de Almeida, immediatamente, propoz a seguinte:-ratio primo, deinde moriamur et in media arma ruamus! Desnecessario é accrescentar que aquelle lemma empolgou o auditorio, ftgurando, por annos-á frente da nossa folha- "A Ordem", e... attestando as ideias dominantes da epoca academica, que, na verdade, eram do mais franco racionalismo. Tudo isso, em tempos que já vão longe e cuja lembrança me desperta gratas recordaçōes, parece-me agora, um sonho rapido e fugaz!

Como decr.n. 1232 , de 2 de Janeiro de $189 \mathrm{I}$, foi creada a cadeira de Philosophia de Direito reunida a de Historia de Direito, a quál, só mais tarde, formou disciplina a parte, pelo decr. n. 3I4, de 30 de Outubro de 1895 , tendo-se, por assim dizer, nestà data, iniciado o ensino especial deste importante ramo de conhecimentos humanos. Esse ensino, pelo seu caracter moderno, tomou novo e differente aspecto, sendo brilhantemente ministrado, até o presente, pelo eminente professor e ex-titular da cadeira, Dr. Pedro Leșsa, auxiliado pelo seu illustrado substituto Dr. João Arruda, cujos talentos os senhores tiveram a opportunidade de conhecer e justamente admirar.

No periodo decorrido, desde 1901 até hoje, posto que affastado desta Faculdade, não tenho me conservado em apathia intellectual, dedicando-me, activamente, não só á advocacia, á politica e á publicidade, como tambem ao ensino, tomando grande parte na fundação da Escola de Commercio Alvares Penteado, cuja monumental construcção se ergue bem fronteira ao nosso velho convento de S. Francisco. Em certa occașião solemne, disse que esses edificios - formando dois corpos salientes, em bella praça, attrahindo em 
nobre e amistoso convivio a mocidade, lembrarão eternamente, Castor e Pollux, não em busca de uma phantasia, qual era o vellocino da mythologia grega, mas, de mãos dadas, á porfia de uma realidade - o progresso nacional, nas suas mais brilhantes manifestações!

-Eis meus senhores, em singelos traços, algumas phases da existencia do vosso novel preceptor, attestando a exactidão do seguinte conceito: que o homem não sabe, desde ao nascer, para onde o destino o conduz; demostrando ainda, a sabedoria do conselho de Shakspeare:- -devemos aproveitar sempre as occasiōes.felizes, porque raras vezes a fortuna volta!

Comquanto tambem preste culto á velha philosophia stoica e, não raro, tenha me conservado firme e impassivel diante dos accidentes da sorte, neste momento, julgo-me numa dessas occasiões propicias. Considero-me feliz, por volver ao gremio de uma mocidade cujas virtudes civicas e predicados moraes, tamanha força e energia dão ao despertar á vida intellectual.

Feliz, tambem porque é com o concurso della, que eu me sinto animado e fortalecido, para desempenhar a difficil missão que me foi confiada e, assim, não deslustrar esta cathedra, tão dignificada pelos meus predecessores e não interromper uma bella tradição academica!

$$
*^{*} *
$$

Snrs. Academicos:

O illustré professor Gilbert Ballet, de uma das principaes academias da velha Europa, em um recente discurso inaugural da cadeira de Historia da Medicina, 
referiu que o famóso anatomista Sténon, tendo de fazer uma conferencia sobre o cerebro, modestamente excusou-se de tão difficil incumbencia nos termos seguintes: — "Au lieu de vous promettre de contenter votre curiosité touchant l'anatomie du cerveau, je vous fais, ici, une confession sincère et publique que je $\mathrm{n}$ y connais rien". Avec la même franchise, (acrescentou Ballet) j'aurai devant vous la même humilité. J'ignore l'histoire de la medicine mais je l'apprendrai pour vons l'enseigner. Cet aveu ne coûte pas à mon amour-propre».

Em identicas circumstanciàs, servindo-me do mesmo conceito daquelles celebres professores, eu vos poderei dizer:- o campo da Philosophia do Direito é tão vasto que, effectivamente, ninguem póde se lisonjear de conhecel-o, ou de tel-o percorrido em toda sua extensão, o:ı talvez mesmo, em sua maior parte! $\mathrm{E}$ senão, attendei-me:

A Philosophia do Direito, antes de tudo, exige que se conheça a philosophia em greval, a sciencia que dá solução a todas as questões, a MATER DISCIPLINARUM. A philosophia constitue o complemento necessario de uma educação liberal; ella dá uma cultura especial e directa á reflexão e á razão, convidando o espirito á meditar sobre os mais intrincados problemas e a formar conviç̧ões, que o devem guiar atravez da senda da vida ( $\mathrm{I}$ ).

$\mathrm{O}$ insigne professor A. Groppali, da Universidade de Modena, em recente livro sobre a Philosophia do Direito, (2) a proposito, assim exprimiu se: "Quest'ultimo gradino della scala ascendente delle generalizzazioni onde la mente umana cerca di spiegarsi il mondo clei fenomeni è rappresentato dalla Filosofia, la quale, rielaborando le conclusioni cui

(1) Dict. Univ. des Sciences et Lettres, pag. 1261

(2) A. Groppali-Filosufia del Diritto, pag. 20 
sono giunte le aitre scienze nei loro singuli dominî, può chiamarsi collo Spencer un sapere totalmente uni. ficato, in contrapposizione al sapere parzialmente unificuto ed al sapere non unificato, rappresentati, come già abbiamo avuto occasione di notare, dalla scienza e dall'empirismo»:

Dizer philosophia, é abranger, desde a genesis, a psychologia, que ensina a decifrar o enigma gravado no templo de Apollo, em Delphos, e resumido nas seguintes palavras-nosce te ipsum; é comprehender a logica, para sabermos as leis do pensamento, na pesquiza e demonstração da verdade; é interpretar a moral, para avaliarmos, entre innumeras theses, aquella formulada pela escola independente, baseada no principio da dignidade pessoal; é, finalmente, circumscrever esse grande oceano, esse oceano immenso, sem limites, da metaphysica, que os discipulos de Aristoteles só estudavam "depois da physica».

Dizer philosophia é saber ainda a qual das escolas philosophicas se deve dar preferencia, para a necessaria unidade mental, ou firme orientação nos estudos. E quão singularmente difficil é chegar-se á essa exclusão ou preferencia, diante do assombroso movimento intellectual hodierno, da incessante renovação de ideias, de leis e de conselhos, renovação ou transformação progressiva, de que, sob pena de clesappare cer, participa a sciencia do direito, tão inseparavel das noções da liberdade e do dever ( $r$ ).

Deixando a philosophia e encarando mais particularmente a Philosophia do Direito, cujo estudo no conceito de Brugi (2) deve fazer parte das disciplinas do ultimo anno academico - quão immensamente vasta

(1) Alfiedo Fouillée-L'Idée moderne du droit, pag. 11.

(2) Biagio Brugi-Introd. Encisl, alle Scienze Giuridiche e Sociali. 
é èssa provincia do saber humano, acerca da qual têm surgido as mais interessantes contendas, as mais variadas controversias!

Para o estudo completo dessa importante sciencia que, no dizer de Vanni, (I) intégra as sciencias juridicas na unidade de seus principios mais geraesem primeiro logar, é preciso ter-se algumas noções propedeuticas das sciencias anthropologicas e sociaes, destacando-se dentre ellas a sociologia, que fixou e $\mathrm{fe} z$ conhecer ao espirito humano, o principio do direito, que outro não é senão: - "a necessidade social organica da limitação proporcionada das actividades voluntarias" como condição elementar da vida collectiva nas proprias sociedades animaes.

Em segundo logar, é indispensavel conhecer, em toda a sua amplitude, os principios fundamentaes dos varios ramos componentes da sciencia juridica. "Do direito privado que se occupa das relações juridicas que interessam principal, directa, immediatamente ao individuo e mediata, indirectamente á sociedade, direito privado que subdivide em varias partes. Do direito publico que se occupa das condições da vida e desenvolvimento que interessam directa, principal e immediatamente á sociedade, e indirecta e mediatamente ao individuo, direito publico geralmente dividido em constitucional, administractivo, judiciario e penal. Do direito internacional que se occupa directa e immediatamente das condições de existencia e progressso dos Estados e mediata e indirectamente dos individuos» (2)... finalmente, das relações intimas de dependencia de cada uma dessas disciplinas entre si para "formarmos uma doutrina que abranja a sciencia do direito em toda a sua vastidão»

(1) Icilio Vanni-Lezioni di Filosofia del Diritto pag. 19.

(2) Dr. Pedro Lessa-A Arte, a Sciencia e a Philosophia do Direito-artigo na Revista da Faculdade, de 1906, pag. 46. 
E' ntesse immenso descortino de ramificações, que se estabelecem as controversias, attestadas por uma multidẳo de obras e monogrophias, que se destacam innumeras theses fundamentaes, cada qual a mais delicada, mais complexa e insoluvel. Tomemos uma, por exemplo, sobre a questão da propriedade singular e da posse: - é util conservar e manter intacta no ensino superior do direito; a tradição romana do direito, que, na linguagem classica, se chama "Dominum ex juire Quitritum" ou semelhante ensino, como pretendem, outros, falsêa e perverte nos espiritos a noção exacta do direito de propriedade? A doutrina romana está ou não em contradição com os principios do direito moderno, da Revolução de I789, inscriptos na declaração dos direitos e dos cidadãos?».(I)

Mas fugindo á digressão e particularisando as idéas:- sendo a philosophia do direito a parte geral da sciencia juridica que determina o methodo applicavel ao estudo scientrfico do direito, expóe os principios fundainentaes dos varios ramos do saber juridico $e$ ensina as relasốes deste com as sciencias anthropologicas e sociaes (2) - surge logo, na primeira plana; a grande questão capital do methodo, a questão, por excellencia, que a nenhum de nós é licito desconhecer, porque interessa mais de perto a cada uma de per si, das varias disciplinas do direito (3). Qual o methodo a adoptar e seguir para a boa direcção do nosso espirito, na formação de uma theoria scientifica e juridica?

"Na philosophia do direito, accrescenta o dr Pedro Lessa, mais do que qualquer outra doutrina, vê-se, claramente, quanto é exacta esta ultima affirmação.

(1) Ernesto Martineau-La Réforme de l'enseignement dans les Ècoles du Droit et la tradition rumaine. Artigo do "Journal des Economistes" (le 1889, tomo XXXVIII, pag. 170.

(2) Dr. Pedro Lessa. - A Arte, a Sciencia e a Philosophia de Direito", artigo na Revista da Faculdade de 1906, pag. 51.

(3) Pietro Cogliolo.-Filosofia del Diritto Privado, pag. 145. 
Se adoptarmos o methodo deductivo dogmatico, que parte das idéas geraes, ministradas pela fé religiosa, ou o methodo deductivo metaphysico, que parte das idéas geraes, dadas pela rasão, qual a concebem os metaphysicos, a doutrina philosophica acerca do direito, que formularmos, será radicalmente diversa da doutrina baseada no methodo scientifico» É tão reconhecida a importancia ou utilidade da methodologia que ella é objecto de um curso especial na Universidade de Berlim.

Contemplando, agora, os immensos thesouros formados pelos estudos contemporaneos e do que, resumidamente, deixamos dito, é o caso de, parodiando Gilbert, em campo opposto, perguntarmos:

- Em face do maravilhoso movimento intellectual moderno e dos progressos dos conhecimentos humanos, quem poderá ter, legitimamente, a pretensão de saber philosophia do direito ?! .

Realmente, é tal o avanço das sciencias sociaes e politicas, tão numerosa a legião de escriptores, tão grande a copia de publicações e tratados, tão estupenda a infinita seria de concepções diversas, de investigações nessa disciplina, que, além das sciencias já referidas, cada vez mais se entrelaça com a demographia, com a psychologia social, com a economia social, com cada uma das sciencias politicas, que (I) não ha senão invocar o celebre-Ignorabimus - do physiologista berlinense Bois-Reymond, citado por Ernesto Hœkel, expressão essa que, si no acertado dizer do commentador, transportado do futuro para o presente-Ignoramus-dá perfeita ideia do estado actual do espirito humano, melhor traduz nossos conhecimentos, em relação á especialidade que vamos nos dedicar. (2)

(1) Icilio Vanni-Lezioni di Filosofia del Diritto-pag. 33 e seguintes.

(2) Ernesto Hokel-Le Monisme, pags. 20, 24 e 45. 
Em taes circumstancias, que nos resta, ao assumir esta cathedra, senão affirmar; mais 'uma vez, o que dissemos, ao entregar, em I 893, a nossa dissertação e theses de concurso á douta Congregação desta Faculdade: -Rem bene, si poteris, si nom, quocumque modo rem.

$$
*^{*} *
$$

Snrs. Académicos:

E' costume tradicional nas Universidades e Academias, costume aliás perpetuado nos institutos de ensino superior do nosso paiz e especialmente nesta Faculdade, por occasião do inicio de cada curso, o titular da respectiva cadeira dar certos esclarecimentos preliminares, em sua lição inaugural, onde por assim dizer, fica traçada a linha geral da conducta a seguir.

Bem me recordo das brilhantes lições inauguraes dos cursos dos meus saudosos lentes Dutra Rodrigues, Sá Benevides, Vieira de Carvalho, Rubino de Oliveira e, após o advento do novo regimen politico, para só me referir aos que já não existem, das notaveis preleç̧ões de abertura das aulas do Dr. Aureliano Coutinho e do Dr. João Monteiro. (I).

No momento presente, á medida de minhas forças, quero observar essa bella tradicção academica. Além do programma já opportunamente distribuido, no qual estão reunidas as principaes theses a serem explanadas durante o anno lectivo, eu, ainda em synthese, vos direi: - em materia de doutrinas ou theorias, quer sobre pontos fundamentaes, quer secundarios da nossa disciplina, não farei empenho em ser, pelos snrs., adoptada e seguida a escola que professo. Todo o meu intuito consistirá em expor com a maior simplicidade e lealdade, as noções geraes das diversas

(1) Dr. Aureliano Coutinho-Revista da Faculdade, de $1 \times 96$. Dr. João Monteiro-Revista da Faculdade, de 1897 
outras escolas, em que, sobre o assumpto da philosophia juridica, se divide, por mil controversias, o pensamento moderno.

Nesse presupposto, prestarei attenção á todas as opiniões, por mais moderadas 'ou exaggeradas que sejam, usando de tolerancia para quantas forem conhecidas, em nossos exercicios praticos, recommendados pelo decr. n. 3903, de I 2 de Janeiro de I 9or, que deu á Faculdade, a organisação, que ella actualmente conserva.

De modo algum, preferirei ouvir affirmações baseadas no magister dixit dos escolasticos da média edade. A liberdade de consciencia, em todas as suas manifestações, a reflexão, o estudo alliado ao nosso proprio exforço, dignificando-nos sempre, serão as nossas melhores armas de combate, neste curto interregno do primeiro anno lectivo, precursor do tirocinio academico.

De accôrdo com o pensar de um escriptor comtemporaneo, (I) cada uma das nossas lições theoricas, em tanto quanto possivel, será immediatamente seguida de applicafóes praticas ou de resumos intuitivos, que tenham por objectivo fixar, de uma vez, em vosso espirito, as ideas explanadas.

O professor não é, para mim, um guia tutelar, que se interpõe á frente do alumno para indicar a vereda a seguir, no terreno escabroso ou difficil de ser palmilhado.

Ao contrario, o professor é, principalmente, um auxiliar, que, apenas deve ministrar, com a possivel exactidão e clareza, as primeiras noções, os principios funda. mentaes, as regras elementares, afim de levar o alumno por si mesmo, em suas constantes locubrações, a descobrir o caminho a trilhar; -é o auxiliar intellectual que

(1) E. Rayot.-Leçons de Psychologie-Avertissement, pag. IV. 
evita, que impede os mesmos de se perturbarem e de se perderem no labyrintho das ideias, ou serem tomados de desalento e vencidos pela apathia.

$\mathrm{E}^{\prime}$ preciso insurgirmos contra os velhos processos, que não têm mais razão de ser! $O$ alumno, longe de ficar sómente com as lições, que lhe transmitte o professor, deve-PELO EXFORÇO PROPRIO-fazer mais do que alguma cousa, frequentando bibliothecas, consultando compendios e expositores. É mister que-va da se, - no dizer de Galiani, com o fim de formar o cabedal scientifico, accumulado pela iniciativa singular, thesouros de conhecimentos, que, mais tarde, muito lhe servirão,nos brilhantes prélios da intelligencia.

Assim pensando, desejo que os snrs. academicos, formados num saudavel e fecundo ambiente de liberdade escolar, sejam todos ou cada qual, a creação de si mesmo, uma personalidade, uma individualidade intellectual-ex se natus-na concisa expressão de Tiberio, segundo Tacito.

Não sei si é pela circumstancia de ter me encontrado absolutamente a sós, em quasi todos os tranzes difficeis da minha vida, que eu me acostumei a achar excellente a posição dos que só contam com a sua propria actividade, com os seus unicos recursos, com o seu exclusivo e supremo exforço!

Ao finalisar, peço aos srs. que sejam continuadores da nossa gloriosa tradicção academica, que tomem nota de um bello conceito do genial Herbert Spencer:-Um ideal, por mais remota que seja a sua realisação, é sempre necessario como um guia. Snrs. academicos:-Está inaugurado o nosso curso de Philosophia do Direito - seja o nosso ideal do presente, o exforço proprio, de par com o exacto cumprimento dos nossos deveres; e o ideal futuro:- tudo pela Patria e pela Republica! 